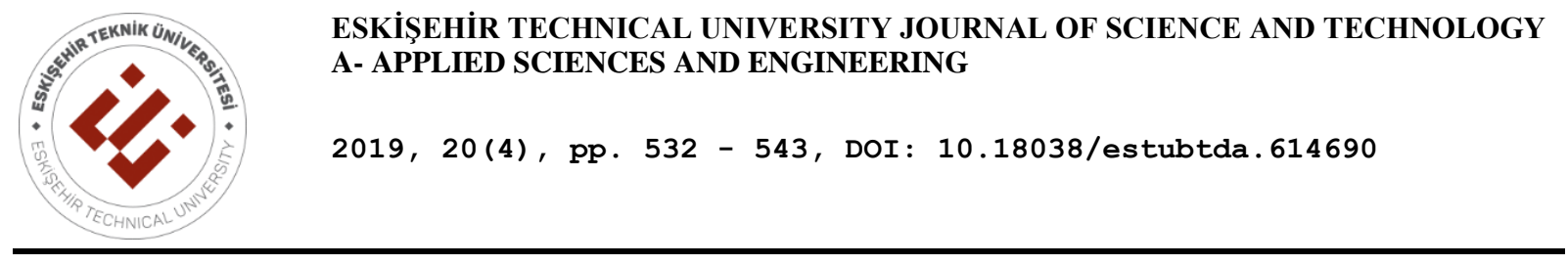

\title{
EFFECT OF IRREGULAR TIME-HISTORY ON THE CYCLIC RESISTANCE OF SAND
}

\author{
Murat TÜRKÖZ ${ }^{1, *}$ Kamil Bekir AFACAN $^{1}$ \\ ${ }^{1}$ Department of Civil Engineering, Engineering Faculty, Eskişehir Osmangazi University, Eskişehir, Turkey
}

\begin{abstract}
The liquefaction behaviors of sandy soils are generally investigated using stress or strain controlled dynamic tests in the laboratory. In terms of ease and applicability of analysis, uniform loading patterns are usually preferred. However, irregular wave forms with different amplitudes and frequencies are generated throughout the soil layers during seismic excitations. In this study, a comprehensive series of cyclic tests have been performed on clean sand samples. Conventional uniform loading and ground-motion records scaled to different cyclic stress ratios were applied to identically prepared specimens. The pore pressure build-up and accumulated strain effects are investigated regarding the effect of the loading type and cyclic stress ratio. The outcome of test series aimed to provide further improvement on dynamic strength approaches for liquefaction assessment, in order to expand its use in current engineering practice. The results have shown that the frequency content plays an important role for the initiation of the liquefaction in terms of the number of cycles to liquefy soil.
\end{abstract}

Keywords: Dynamic triaxial test, Irregular loading, Excess pore water pressure, Sand particles

\section{INTRODUCTION}

Estimation of dynamic behavior of soils under seismic excitations is a major concern in the design of engineering structures. A wide variety of field and laboratory techniques are available for this purpose each with having different advantages and limitations with respect to different problems. In the last century, a significant progress has been done in terms of identifying soil liquefaction and associated ground failures $[1,2]$.

Since they are quick and relatively easy to perform, in-situ testing techniques are mostly preferred to determine the liquefaction susceptibility. The cyclic resistance ratio is an important dynamic characteristic and is related to parameters obtained from SPT, CPT and Vs measurements. Although various correlations were developed based on the current data bases taken from several sites [3,4], there are two major drawbacks of in-situ testing. First of all it is not possible to determine the pore water pressures (except some CPT models). And the propagation of cyclic shear waves with irregular shear stress time histories (with different frequencies and amplitudes) during an earthquake cannot be applied for in-situ testing. One approach to overcome this problem is the use of constitutive soil models. However these models based on in-situ tests are only capable of predicting the excessive pore water pressure and permanent deformation to small-moderate strain range. Therefore, the calculated surface deformations will be approximations [5]. Correct modelling and calculation of the excess pore water pressure is an important key point in liquefaction definition which can only be accomplished by laboratory element testing. Moreover, laboratory tests are expensive, time consuming, and have some disadvantages in terms of simulating the material properties. However they provide a more accurate model of in-situ static and dynamic loading conditions for a wide range of stress or strain amplitudes [6-9].

The liquefaction susceptibility based on laboratory testing is defined by two different criteria. The first definition is by [10] in which the number of cycles needed where the excess pore water pressure approaches or equals to the initial effective confining stress (initial liquefaction). This is commonly done by defining a "cyclic stress ratio" term. From the previous strong motion records having a magnitude higher than 7.0, it is known that the dominant number of cycles causes any damage changing 10-20 [10]

*Corresponding Author: mturkoz@ogu.edu.tr

Received: 03.09.2019 Published: 30.12.2019 
defined "cyclic resistance ratio" term as the "cyclic stress ratio" that would result in liquefaction after 15 cycles whereas [11] used 20 cycles. The logic behind this method is to evaluate the cyclic shear stresses caused from the upward propagation of cyclic shear waves at any point of a soil deposit. Ishihara and Yasuda [11] also defined the liquefaction in terms of strain levels, which equals to about 5\% double amplitude axial strain. To evaluate these parameters a single frequency with uniform sin-loading pattern is used in the laboratory tests. The test results are then plotted for different cyclic stress ratio values. The cyclic resistance ratio is determined as the cyclic stress ratio causing liquefaction in 15 or 20 cycles. Some correction factors are introduced to convert the irregularity, direction and variation of actual loading conditions during seismic excitations. However the different amplitudes and frequency contents of strong ground motion records raise a question about the applicability of the 5\% strain criteria [12,13, and 14].

In this study a series of cyclic triaxial (CTX) tests were performed to investigate effects of loading patterns. In the first series of tests samples prepared at constant relative densities were subjected to different earthquake ground motion histories having different predominant periods. In the second test of series, identical samples as in the first series were subjected to uniform cyclic loading under different cyclic stress ratios.

\section{MATERIALS AND METHODS}

\subsection{Material}

All tests were conducted on standard silica sand, which is uniform, fine-grained, rounded sand and classified as poorly graded sand (SP) according to the Unified Soil Classification System (USCS) [15]. The mean particle size $D_{50}$ is evaluated as $0.78 \mathrm{~mm}$, and the coefficient of uniformity $\left(c_{u}\right)$ and the coefficient of curvature $\left(\mathrm{c}_{\mathrm{c}}\right)$ are calculated as $0.19 \mathrm{~mm}$ and $1.79 \mathrm{~mm}$, respectively.

\subsection{Testing Device}

The CTX tests were conducted using a servo-controlled pneumatic triaxial apparatus by Wykeham Farrance. The testing system is capable of performing stress or strain controlled loading tests with predefined irregular or uniform loading conditions. The maximum cell pressure capacity is of the system is $10 \mathrm{kgf} / \mathrm{cm}^{2}$ and the maximum axial load that can be applied is $200 \mathrm{kgf}$.

\subsection{Determination of the Loading Shapes}

Earthquake records are described by three time histories; acceleration, velocity and displacement. In laboratory tests, uniform loading has been a common practice in terms of simplicity. In this study along with uniform loading five ground motion time histories were used. The acceleration time histories used to derive the displacement time histories for each motion. The details of the earthquake records are shown in Table 1.

Table 1. List of earthquake records obtained from different sources

\begin{tabular}{lllllll}
\hline Motion & Record Seq. \# & Date & Magnitude & Rjb $(\mathrm{km})$ & Rrup $(\mathrm{km})$ & Related Data \\
\hline Coyote Lake & 147 & 1979 & 5.74 & 8.47 & 9.02 & Type 1 \\
Loma Prieta & 766 & 1989 & 6.93 & 10.38 & 11.07 & Type 2 \\
Kobe, Japan & 1106 & 2995 & 6.90 & 0.94 & 0.96 & Type 3 \\
Kocaeli, Turkey & 1176 & 1999 & 7.51 & 1.38 & 4.83 & Type 4 \\
Northridge-01 & 1012 & 1994 & 6.69 & 9.87 & 19.07 & Type 5 \\
\hline
\end{tabular}

The tests were performed under deformation controlled cyclic loading conditions by using displacement time histories of the events. Figure 1 shows the strong motion record of Kocaeli Earthquake and its corresponding velocity and displacement histories. 

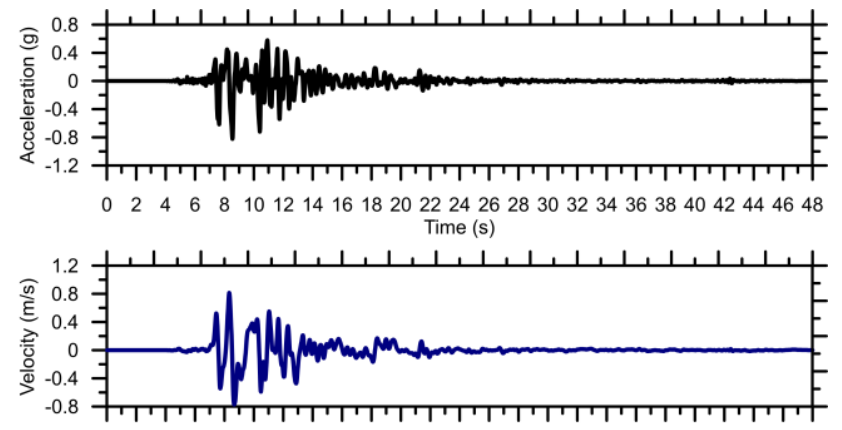

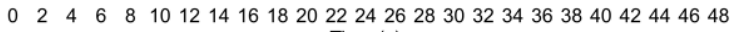
Time (s)

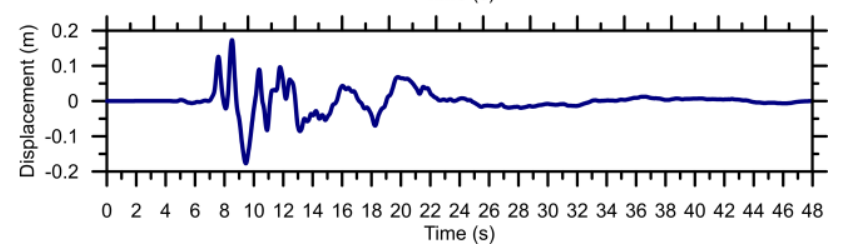

Figure 1. Acceleration, velocity and displacement time series for Kocaeli Earthquake

Comparisons of the loading shapes used in the tests are presented in Figure 2 along with the sinusoidal loading. Peak to peak amplitude of the axial load were scaled desired cyclic stress ratios, CSR and used for all loading types.

As seen in Figure 2 each type of loading has its own time content characteristics. Figure 3 shows the spectral acceleration histories and the frequency content calculated from the fast Fourier transformations of the strong motions. The predominant frequency $\mathrm{T}_{\mathrm{p}}$, is described as the period at which the maximum spectral acceleration observed. $T_{p}$ values of the loading patterns vary between $0.46 \mathrm{~s}$ to $4.42 \mathrm{~s}$.
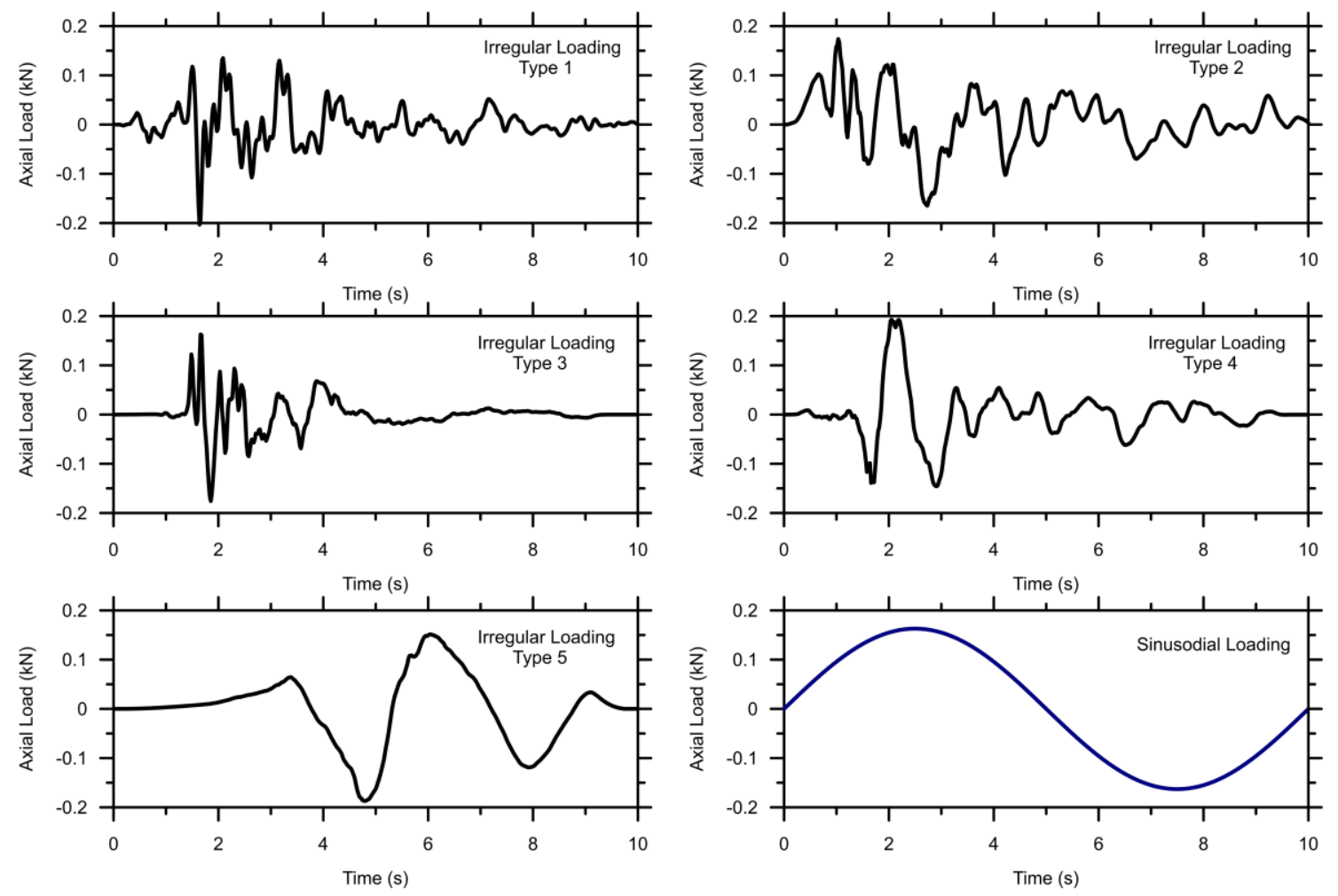

Figure 2. Different Loading shapes used in the study 


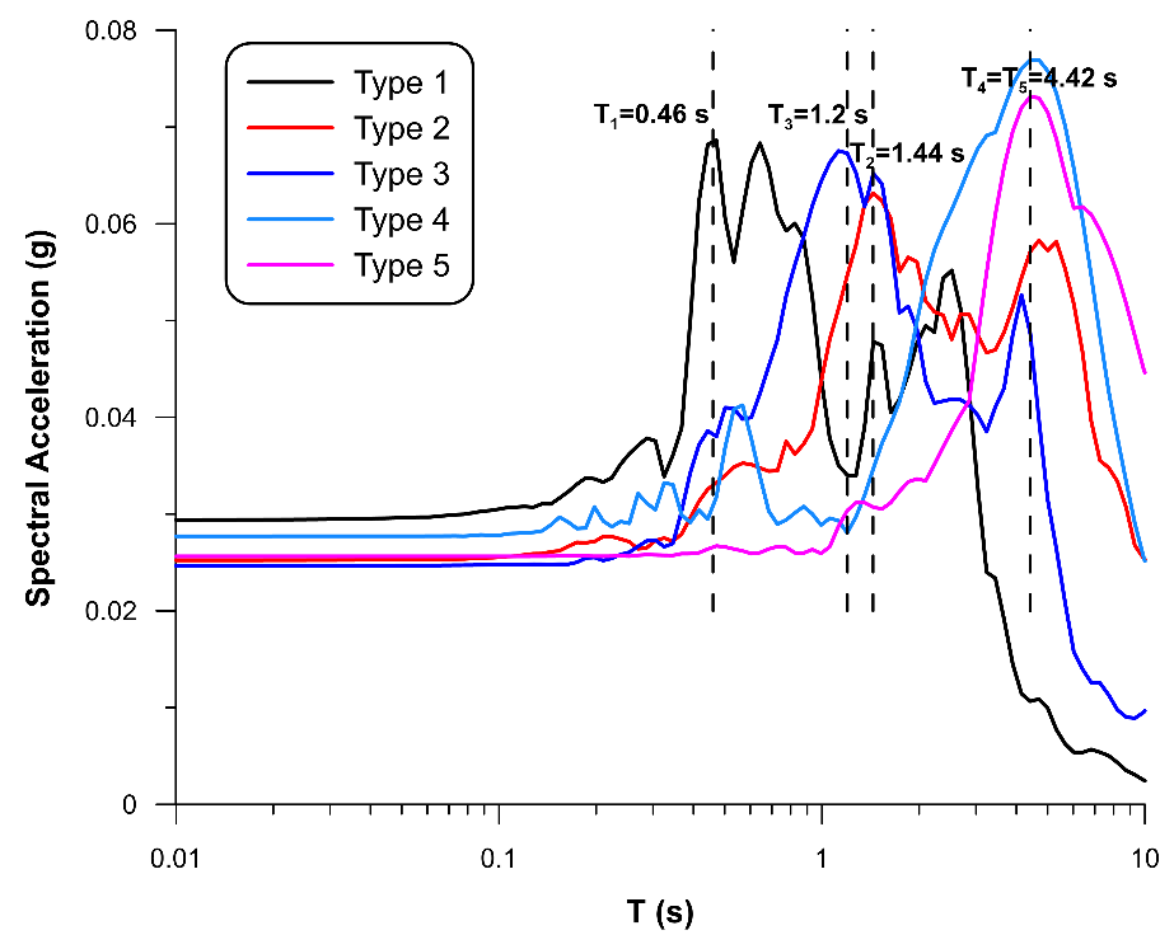

Figure 3. Spectral acceleration and predominant periods of the ground motions

\subsection{Sample Preparation}

A series of six CTX tests (at three different CSRs for each series) were performed at a constant relative density $\left(\mathrm{D}_{\mathrm{r}}=40 \%\right)$. All samples were consolidated to a confining pressure of $65 \mathrm{kPa}$ [16].

It is known that liquefaction resistance of sand can vary widely depending on sample preparation methods. $[17,18,19]$ prepared samples of sand employing dry vibration, wet vibration, dry tamping, and wet tamping methods and reported that the method of sample preparation had a profound effect on the dynamic behavior of sand. Thus it is important to select an appropriate method for sample preparation. Moist tamping (MT) method has been selected for the purpose. In terms of material structure, sand specimens formed by MT method are more isotropic than other preparation methods. For this purpose sand sample at a predetermined mass was mixed in a bowl with water (at a water content of 5\%), and then compacted in five layers into a split mold. Identical samples were prepared having a diameter of $70 \mathrm{~mm}$ and a height of $143 \mathrm{~mm}$. Saturation was performed using stepwise back pressure technique as suggested in ASTM 15 2000. The saturation degree was controlled by checking the B value of 0.95 or greater. The effective lateral stress was increased to the predetermined stress value incrementally in order to prevent vertical and horizontal displacement. The samples were then consolidated for 30 minutes. 

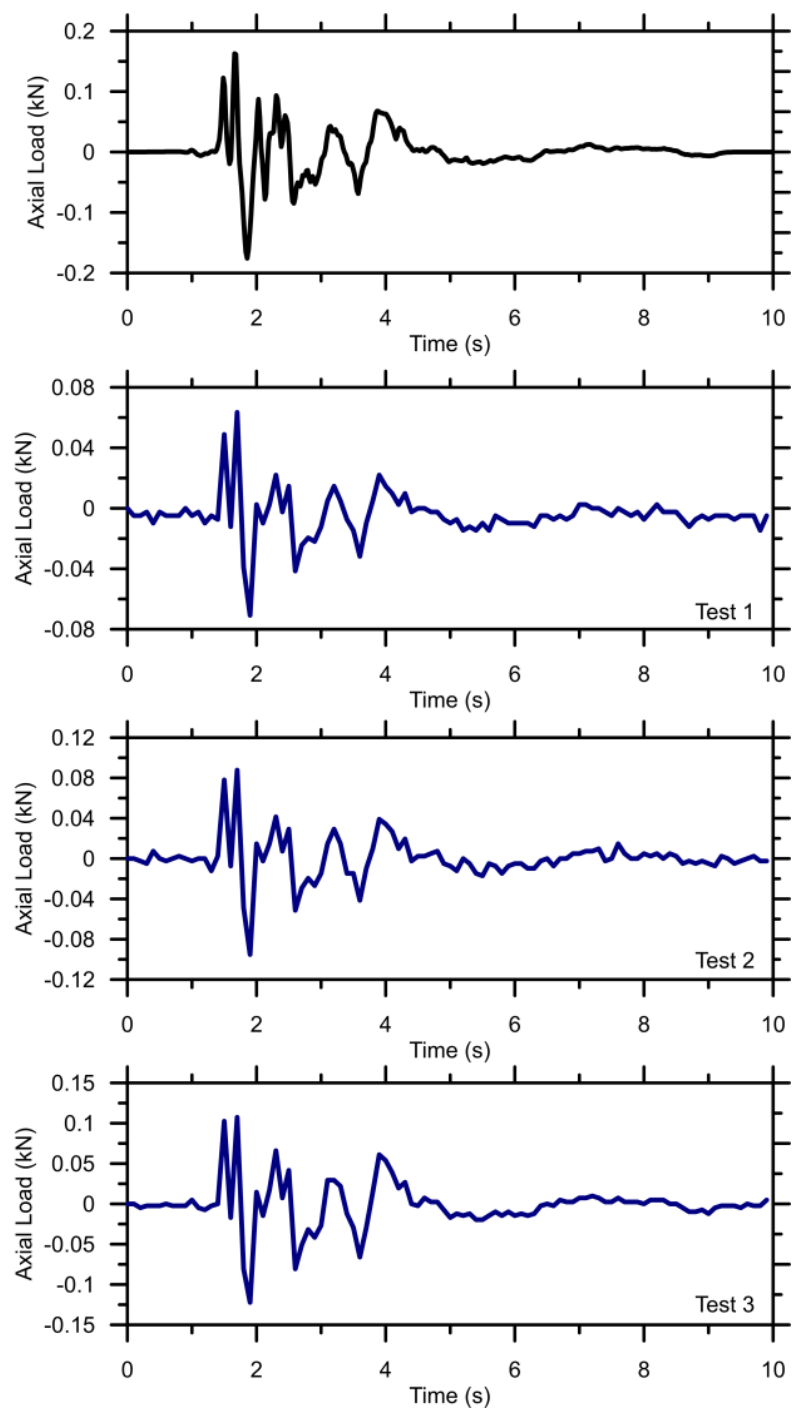

Figure 4. Performance of the CTX for different loading amplitudes

Before testing, the equipment was checked if it was calibrated correctly. For this purpose, a dummy sample subjected to one of the loading types at different loading magnitudes. The input stress time series were compared with the output data (Figure 4). As seen in the figure although there is some noise after $6^{\text {th }}$ second, it is seen that the shape of the input load was simulated perfectly for different loading amplitudes.

\section{RESULTS AND DISCUSSION}

The samples were cyclically loaded at six different stress-time histories (five displacement time histories and uniform loading pattern as described above). In the first series the tests were performed by setting the cyclic stress ratio not big enough (the cyclic stress ratio was set to CSR=13.46\%) to initiate liquefaction immediately. The time history of displacements recorded at 1979 Coyote Lake earthquake which has a predominant period of 0.46s were used. Development of pore water pressure and strains were recorded and presented in Figure 5. It can be seen from the Figure 5 that the pore water pressure generation is constantly increasing whereas the axial deformation is so small to the time when the pore pressure equals to the confining pressure. Thereafter deformation of the sample suddenly increases as expected which is the initiation of liquefaction (in 336 cycles). In the next series of the test, the same time history but with an increased cyclic stress ratio of $19 \%$ was applied to an identically prepared 
sample. The test results are shown in Figure 6. The pore water pressure continuously developed and become equal to the initial confining after 40 cycles. At the same time the axial strains developed to $8 \%$. In the third series of the tests the cyclic stress ratio was increased to $31 \%$ to the third identical sample. This time the pore water pressure rapidly increased in the first two cycles and become equal to confining pressure. The axial strain was about $4 \%$. It can be seen that the liquefaction occurs nearly the same time as the initiation of peak value of stress time history.
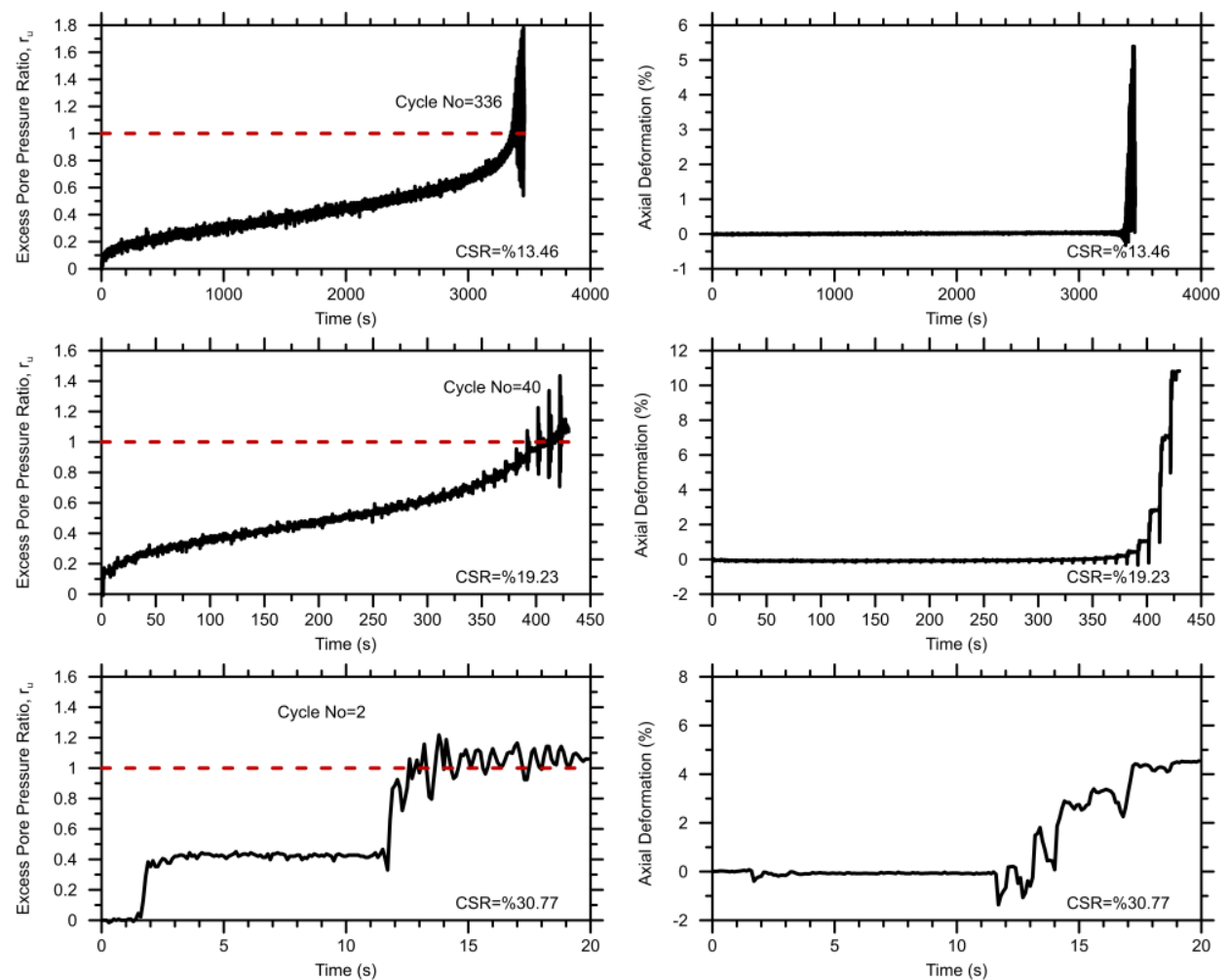

Figure 5. Excess pore pressure generation and corresponding axial deformations obtained from the tests under different CSRs for Type 1 (Coyote)

Figure 6 shows the results of 1989 Loma Prieta (Station 766) earthquake time history loading test. The predominant period of the motion is $1.44 \mathrm{~s}$. The amplitude of time history was the same as with the previous test $(\mathrm{CSR}=13 \%)$ not big enough to initiate liquefaction quickly. Therefore the axial strains are almost zero even if there is an increase in pore water pressure. It can be seen from the Figure 7 that the strains become significantly large only after the excess pore water pressure become equal to the confining pressure (in 466 cycle). In the second test series on an identical sample the CSR increased to a value of $19 \%$. At this time the sample has reached the liquefied state after 16 cycles and the axial shear strains developed up to $10 \%$ after the initiation of liquefaction. In the first two tests the pore pressure development continuously however the amount of axial strains was not big enough until liquefaction. However in the third series where the cyclic stress ratio equals to $30 \%$ the sample was liquefied at the $3^{\text {rd }}$ cycle. 

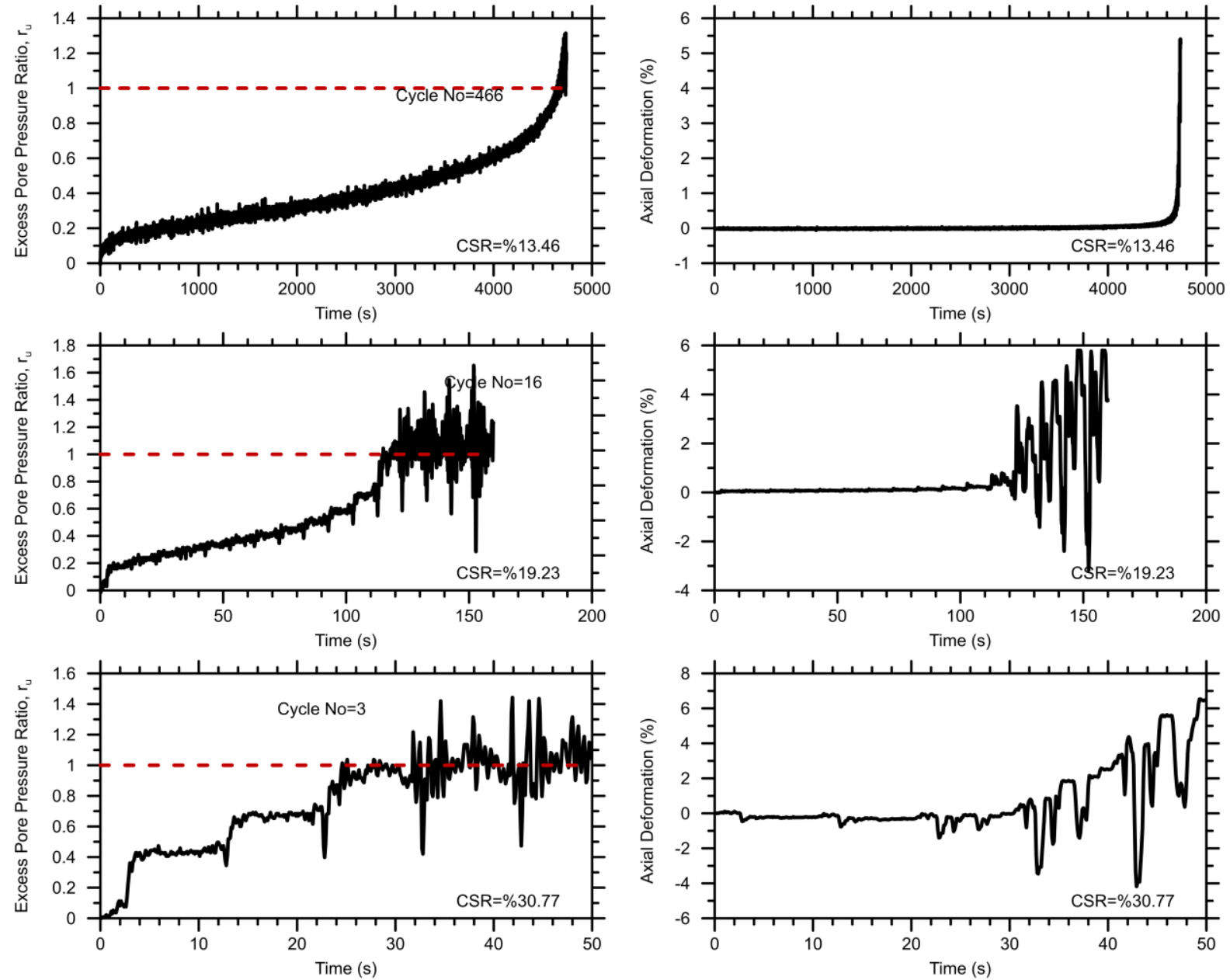

Figure 6. Excess pore pressure generation and corresponding axial deformations obtained from the tests under different CSRs for Type 2 (Gilroy)

Another series of test were conducted by using the time history of 1995 Kobe earthquake which has a peak dominant period of $1.2 \mathrm{~s}$. is shown in Figure 7. The pore pressure and the strain behavior are very similar to Loma Prieta earthquake as two of the strong motion records have similar predominant periods. The liquefaction took place at the same cycle levels.

The fourth and fifth series of tests are performed using the records of 1999 Kocaeli and 1994 Northridge earthquakes which both have predominant periods of $4.42 \mathrm{~s}$. The general trend for pore pressure development and strains are the same for both loadings specifically for the cyclic stress ratio's of $13 \%$ and 19\% (Figure 8 and Figure 9). If the level of cyclic stress ratio becomes sufficiently large such as $\mathrm{CSR}=30 \%$, the effect of predominant period disappears. 
Türköz and Afacan / Eskişehir Tech. Univ. J. of Sci. and Technology A-Appl. Sci. and Eng. 20 (4) - 2019
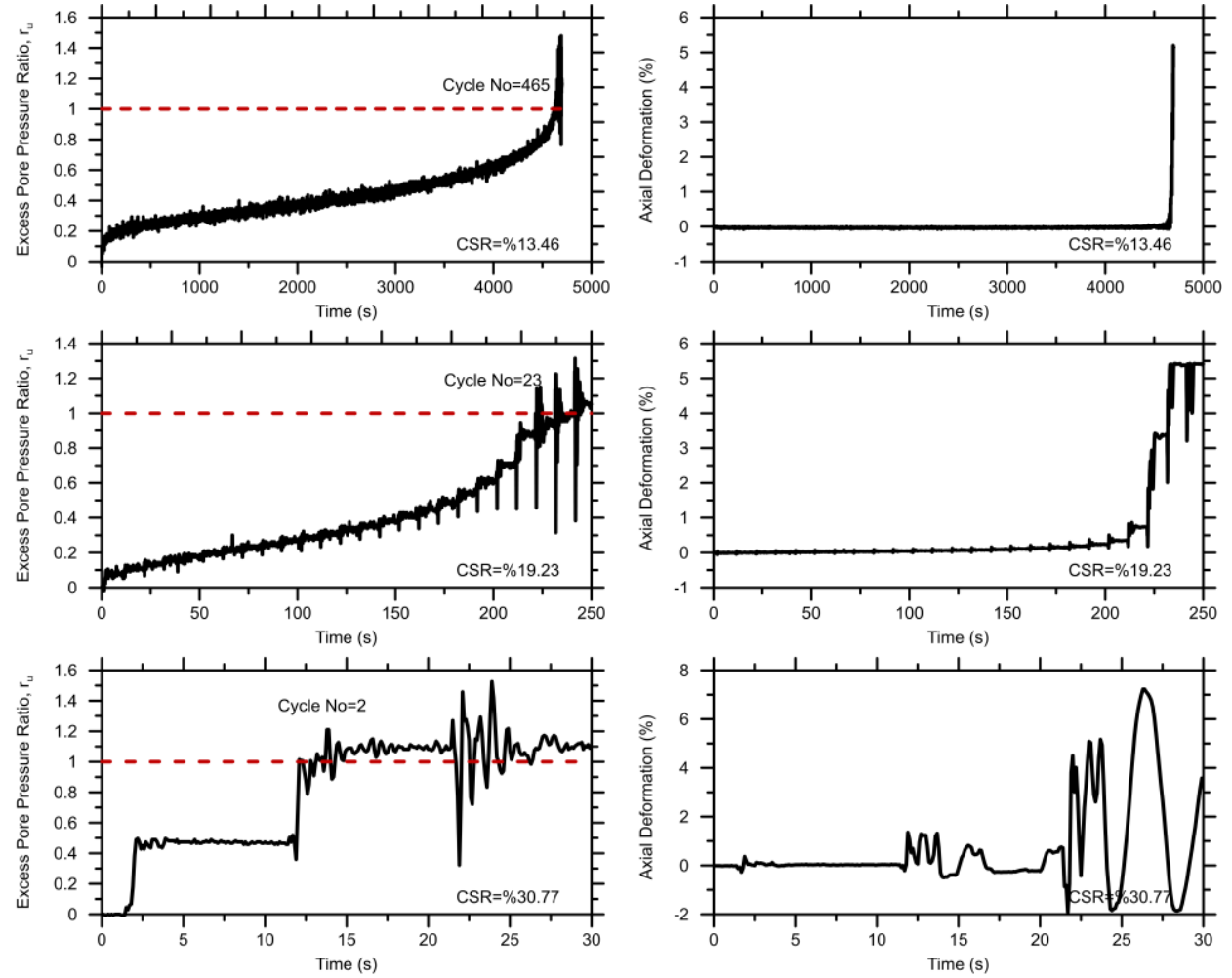

Figure 7. Excess pore pressure generation and corresponding axial deformations obtained from the tests under different CSRs for Type 3 (Kobe)
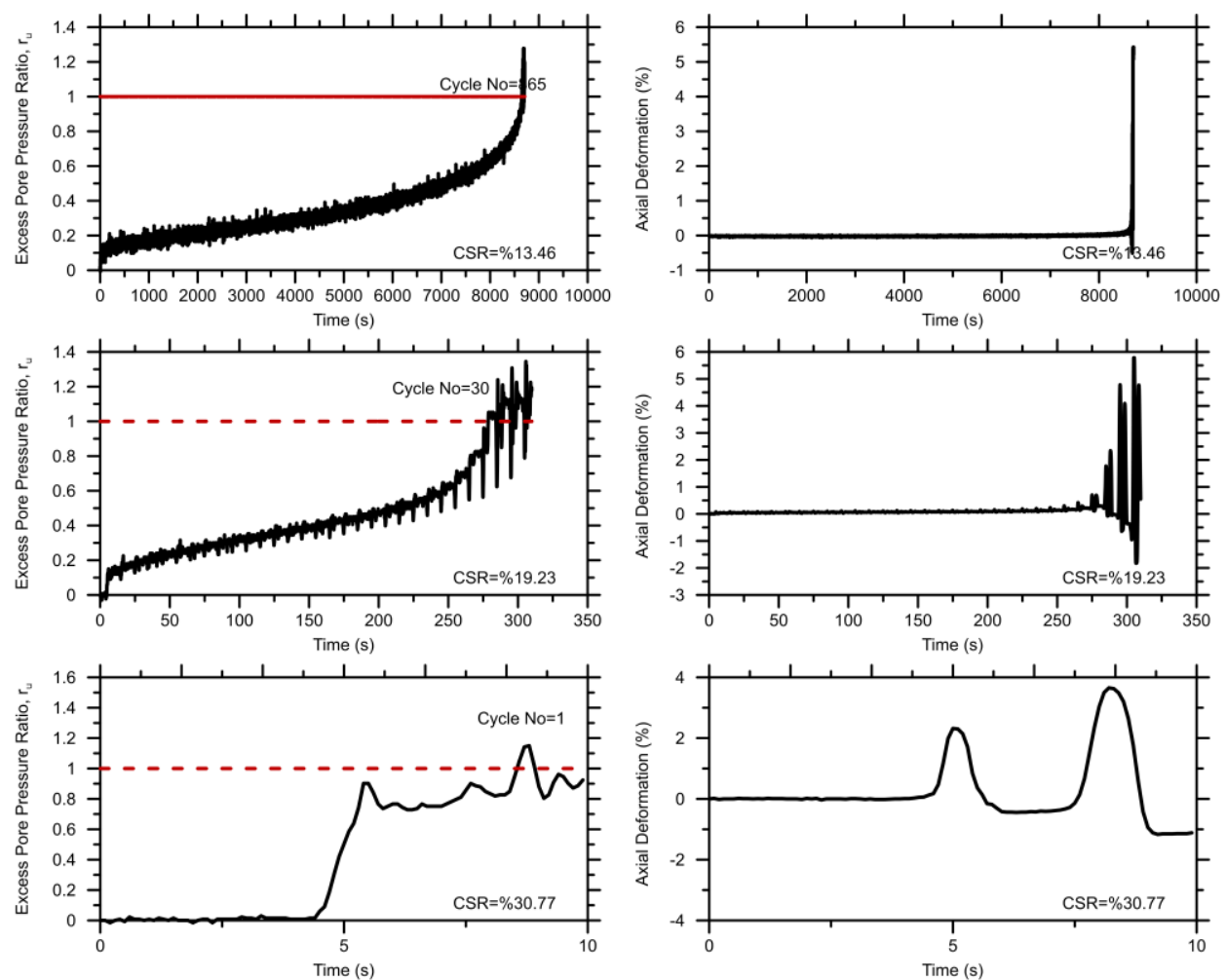

Figure 8. Excess pore pressure generation and corresponding axial deformations obtained from the tests under different CSRs for Type 4 (Kocaeli) 

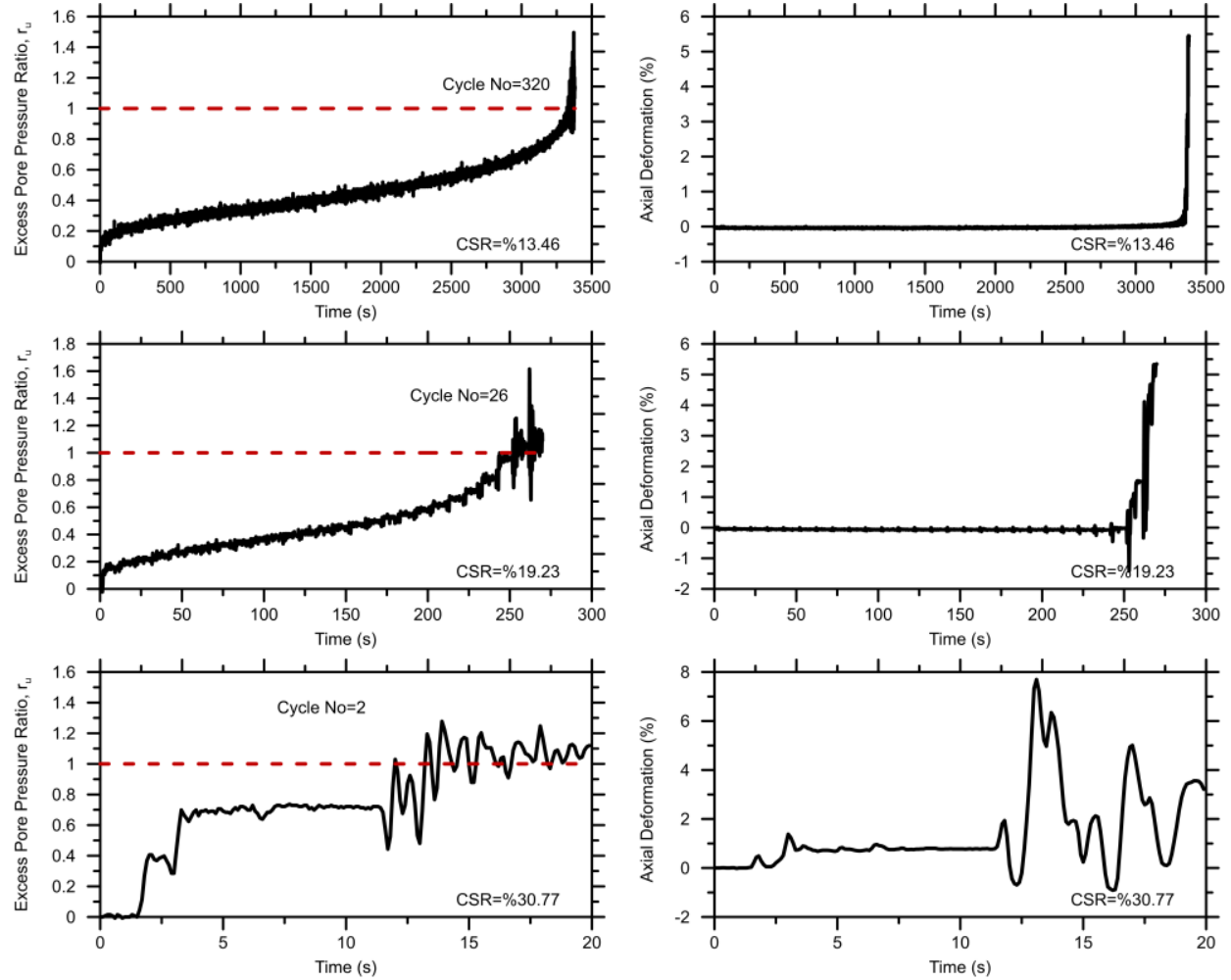

Figure 9. Excess pore pressure generation and corresponding axial deformations obtained from the tests under different CSRs for Type 5 (Northridge)

In the course of strong motion histories, it is possible to locate a point in the curve where cyclic stress ratio is defined. To this end the last series of the tests were performed in the same manner as above under sinusoidal uniform loading (Figure 10).

It is known that an important factor classifying the degree of stability of sand soils during seismic events is the cyclic stress ratio. During the time history loading the strain induced in the sand changes not only with the level of cyclic stress ratio but also with predominant frequency. Thus it is required to have a definition about how to characterize the amount of cyclic strength is an important issue especially under strong motion histories. By adopting the definition of liquefaction to the test results an illustration is presented in Figure 11. As seen from the figure the cyclic stress ratio obtained from sinusoidal loading is bigger than the strong motion histories between $13 \%$ and $25 \%$ which leads to somewhat conservative design. 
Türköz and Afacan / Eskişehir Tech. Univ. J. of Sci. and Technology A-Appl. Sci. and Eng. 20 (4) - 2019
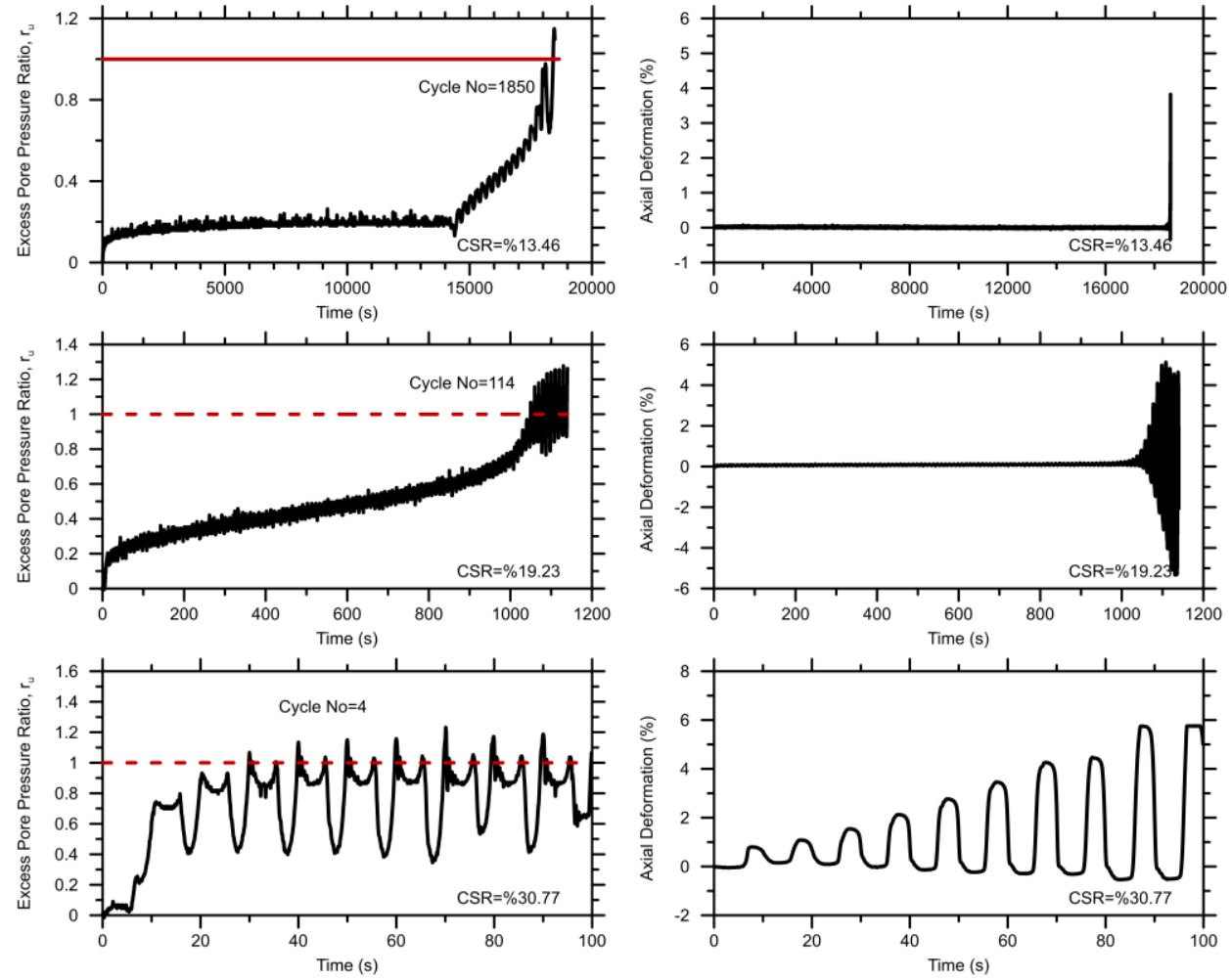

Figure 10. Excess pore pressure generation and corresponding axial deformations obtained from the tests under different CSRs for Sin loading.

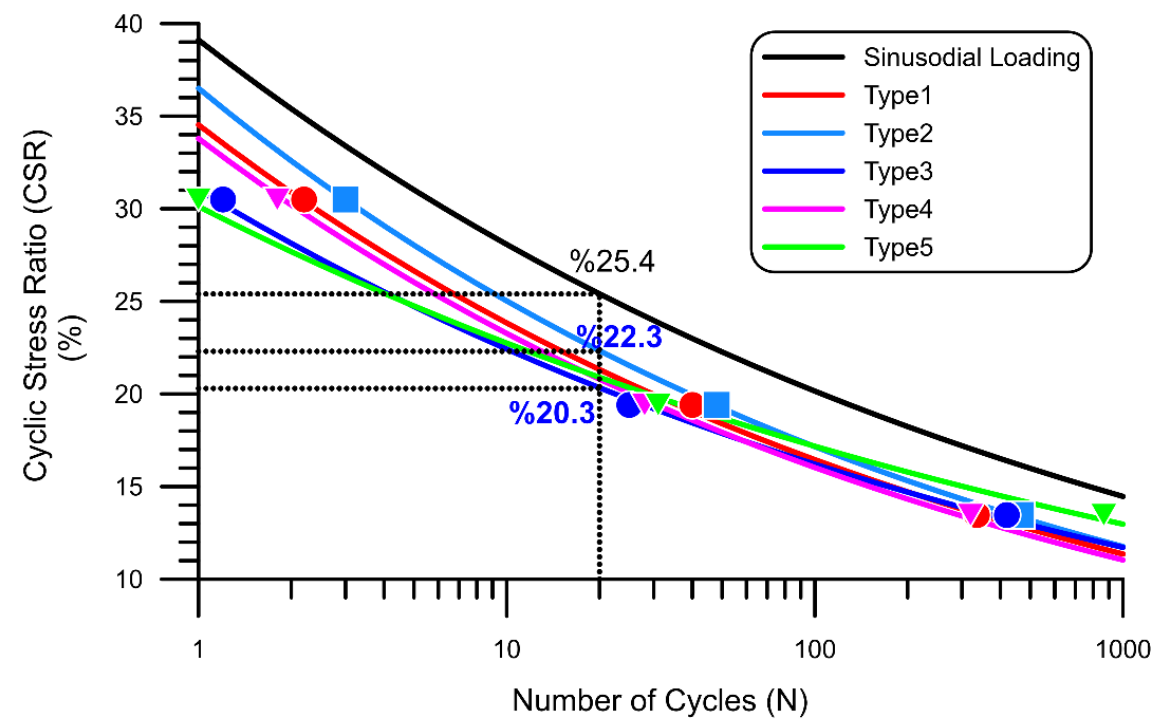

Figure 11. Determination of the CRRs for different loading types

The average curves in Figure 11 shows the cyclic resistance ratio values causing 5\% strain in 20 cycles. It may be seen that the test data regarding the irregular time history lie $13-25 \%$ below the uniform loading data. 


\section{CONCLUSION}

In this study a series of cyclic triaxial tests were performed on clean sand samples under irregular time histories and the results compared with uniform cyclic loading pattern. The tests were performed under same effective pressures and relative density. The displacement-time series generated form acceleration time series were scaled and applied for three different cyclic stress ratio levels. The variation of excess pore water pressure and axial strains were recorded. In each series of tests it was observed that the time required for the initiation of liquefaction under irregular load conditions is less than compared to uniform loading. Based on the test results the cyclic stress ratio levels to initiate liquefaction are calculated. The cyclic stress ratio level to initiate liquefaction under uniform loading is found to be $28 \%$ greater than the irregular loading. A reason for this might be the frequency content. However there are other effects such as predominant period of the ground motion, duration, or arias intensity which needs to be studied.

\section{REFERENCES}

[1] Finn WDL. State-of-the-art of geotechnical earthquake engineering practice. Soil Dyn Earthquake Eng 20(1):1-15 (2000).

[2] Kramer SL. Geotechnical earthquake engineering. Upper Saddle River, NJ: Prentice-Hall(1996).

[3] Idriss RW, Boulanger W. Semi-empirical procedures for evaluating liquefaction potential during earthquakes. Soil Dyn Earthquake Eng 26: 115-130 (2006).

[4] Giretti D, Fioravante V. A correlation to evaluate cyclic resistance from CPT applied to a case history. Bulletin of Earthquake Engineering (2016).

[5] Kwan WS, Sideras S, El Mohtar, C, Kramer S.:Pore pressure generation under different transient loading histories. Tenth U.S. National Conference on Earthquake Engineering Frontiers of Earthquake Engineering July 21-25, Anchorage, Alaska. (2014)

[6] Seed HB, Idriss IM.: Soil moduli and damping factors for dynamic response analyses. Report no. EERC 70-10, Earthquake Engineering Research Centre, University of California, Berkeley (1970)

[7] Iwasaki T, Tatsuoka F, Takagi Y. Shear modulus of sands under torsional shear loading. Soils and Foundations 18(1):39-56 (1978).

[8] Ishibashi I, Zhang X. Unified dynamic shear moduli and damping ratios of sand and clay. Soils and Foundations, 33(1):182-191 (1993).

[9] Bol E, Önalp A, Arel E, Sert S, and Ozocak A. Liquefaction of silts: the Adapazari criteria. Bulletin of Earthquake Eng. 8: 859 (2010)

[10] Seed HB, Lee KL. Liquefaction of saturated sands during cyclic loading. J Soil Mech Found Div ASCE, 92(6):105-134 (1996)

[11] Ishihara K, Yasuda S.: Soil liquefaction under random earthquake loading condition. Proceedings of 5th world conference earthquake engineering. ASCE, Rome, pp 329-338 (1973).

[12] Kirar B, Maheshwari BK.: Effects of silt content on dynamic properties of Solani sand. Seventh international conference on case histories in geotechnical engineering, Chicago (2013) 
Türköz and Afacan / Eskişehir Tech. Univ. J. of Sci. and Technology A-Appl. Sci. and Eng. 20 (4) - 2019

[13] Kumar SS, Dey A, Krishna AM. Response of saturated cohesionless soil subjected to irregular seismic excitations. Natural Hazards 93: 509-529 (2018).

[14] Kumar S, Krishna AM, Dey A. Evaluation of dynamic properties of sandy soil at high cyclic strains. Soil Dyn Earthq Eng 99:157-167 (2017).

[15] ASTM D2487. Standard practice for classification of soils for engineering purposes (unified soil classification system). ASTM International, West Conshohocken (2006)

[16] ASTM D5311. Test method for load controlled cyclic triaxial strength of soil. Annual book of ASTM standards. ASTM International, West Conshohocken (2011).

[17] Ladd RS. Specimen preparation and cyclic stability of sands. Journal of the Geotechnical Engineering Division, ASCE 103: 535-547 (1977).

[18] Yang Z X, Li XS, and Yang J. Quantifying and modelling fabric anisotropy of granular soils. Geotechnique 58(4): 237-248 (2008).

[19] Sze HY, Yang J. Failure Modes of Sand in Undrained Cyclic Loading:Impact of Sample Preparation. Journal Of Geotechnical And Geoenvironmental Engineering ASCE, 140:152-169 (2014). 